\title{
LITERATURA Y ARTE LATINOAMERICANOS HOY: ¿BOOM O BURBUJA?
}

LATIN AMERICAN ART AND LITERATURE TODAY: BOOM OR BUBbLE?

Yvette Sánchez

Universität St. Gallen

St. Gallen, Suiça

\section{Resumen}

El presente artículo intenta caracterizar el reemplazamiento de las letras latinoamericanas por las artes visuales, en lo referido a su proyección internacional, en el último medio siglo. Mientras que el Boom latinoamericano de la literatura de los años 60 se extinguía paulatina y casi imperceptiblemente, hay críticos que afirman que la difusión, la demanda en el mercado y el explotado valor monetario de las artes visuales amenazan con desaparecer repentinamente. Este fenómeno suele evocarse a través de la metáfora de la burbuja, que examinamos aquí en sus múltiples facetas, económicas, artísticas y literarias. Como motivo, dicha imagen plástica de fragilidad ilustra la fugacidad y, en clave paradójica, la violencia. Con respecto a los procesos descritos en este artículo, también cabe preguntarse hasta qué punto es la demanda del mercado la que crea y consolida movimientos o programas estéticos colectivos y homogeneizantes. El éxito repentino y masivo de canonización, notoriedad y circulación siempre puede obrar de catalizador en la formación de escuelas. En América Latina, el boom con impacto global fomenta asimismo una orientación panamericana y transnacional. Influyentes curadores, coleccionistas y ferias contribuyeron de manera decisiva a sacar las artes visuales de una difusión reducida, más bien fragmentaria, rizomática de individuos, en la que precisamente se mueven actualmente los literatos.

Palabras claves: Arte y literatura latinoamericanos; Boom; burbuja; fugacidad; transnacionalización; mercado; difusión; canon; Valeria Luiselli y Teresa Margolles.

\section{Abstract}

This article aims to trace the relay of Latin American literature by the visual arts as to its international diffusion within half a century. While the Latin American literary Boom of the 60s was extinguished gradually and almost imperceptibly, there are critics who claim that the market distribution and demand as well as exploded monetary value of the visual arts threaten to disappear all of a sudden. This phenomenon is evoked through the metaphor of the bubble, which we examine

\section{Resumo}

O presente artigo tenta caracterizar a substituição das letras latino-americanas pelas artes visuais, no que se refere a sua projeção internacional, nos últimos cinquenta anos. Enquanto o Boom latino-americano da literatura dos anos 60 se extinguia paulatina e quase imperceptivelmente, há críticos que afirmam que a difusão, a demanda no mercado e o disparado valor monetário das artes visuais ameaçam a desaparecer repentinamente. Este fenômeno costuma ser evocado através 
here in its multiple economic, artistic and literary facets. As an artistic device the plastic image of fragility can paradoxically illustrate violence, besides fugacity. In the processes described in this article, we may ask the question to what extent it is the market demand which creates or strengthens homogenizing movements or collective and aesthetic programs. The sudden and massive success through canonization, fame, and circulation can always act as a catalyst in the formation of aesthetic schools. In Latin America, the Boom with its global impact also promotes a pan-American and transnational orientation. Influential curators, collectors and art fairs contributed decisively to remove the visual arts from a rather fragmentary, rhizomatic, reduced diffusion of individuals, in which literary writers are currently moving.

Keywords: Latin American art and literature; boom; bubble; fugacity; transnationalization; market; dissemination; canon; Valeria Luiselli and Teresa Margolles. da metáfora da bolha, que examinamos aqui em suas múltiplas facetas: econômicas, artísticas e literárias. Como motivo, a referida imagem plástica de fragilidade ilustra a fugacidade e, de modo paradoxal, a violência. Com relação aos processos descritos neste artigo, também cabe perguntar até que ponto a demanda do mercado é responsável pela criação e consolidação dos movimentos ou programas estéticos coletivos e homogeneizantes. O sucesso repentino e massivo de canonização, notoriedade e circulação sempre pode atuar como catalisador na formação de escolas. Na América Latina, o boom com impacto global fomenta também uma orientaçáo panamericana e transnacional. Influentes curadores, colecionadores e feiras contribuíram de maneira decisiva para tirar as artes visuais da uma difusão reduzida, muitas vezes fragmentária, rizomática de indivíduos, na qual precisamente se movem atualmente os literatos.

Palavras-chave: Arte e literatura latino-americanas; Boom; bolha; fugacidade; transnacionalização; mercado; difusão; cânone; Valeria Luiselli e Teresa Margolles.

La figura del quiasmo marca la situación del arte y de la literatura en América Latina, de hace medio siglo y la actualidad. Mientras había conciencia de grupo y de boom literarios en los años 60, el arte de aquella época disponía principalmente de individuos sobresalientes pero dispersos: Fernando Botero (Colombia), Osvaldo Guayasimín (Ecuador), Wilfredo Lam (Cuba), Roberto Matta (Chile) o Luis Camnitzer (Uruguay), y apenas desempeñaba un papel en la escena internacional. El muralismo mexicano sería la excepción en la primera parte del siglo XX, ya que sus artistas, con una pintora y una fotógrafa como artistas afiliadas, formaron escuela. Diego Rivera, David Alfaro Siqueiros, José Clemente Orozco, Rufino Tamayo, Frida Kahlo y Tina Modotti son los nombres de esta escuela nacida in situ. En los años 60 y 70 , aunque importado de París, el arte cinético venezolano tendría un éxito internacional considerable bajo la égida de Jesús Rafael Soto, Carlos Cruz-Diez y Alejandro Otero, al lado del argentino Julio Le Parc.

Durante todo el siglo XX, tanto el mismo arte como su recepción y crítica siguieron apegados a una orientación nacional surgida con la Independencia 
en el siglo anterior. Sólo en el siglo XXI, han emergido una demanda internacional de arte latinoamericano y un naciente boom, mientras, por otro lado, mengua la demanda internacional de literatura latinoamericana.

Varias iniciativas han obrado de catalizadores de un giro transnacional en el continente frente a las artes visuales, y de una entrada en el mercado global: la feria Art Basel Miami, curadores como Pablo León de la Barra, del Museo Guggenheim de Nueva York (1972, México D.F.) o coleccionistas privados como Ella Fontanals Cisneros (Miami /Caracas/La Habana) y la Colección Daros.

Boom del arte contemporáneo: los impulsadores

Bajo el título programático Bajo un mismo sol/Under the same Sun: Art from Latin America Today, el curador del Solomon R. Guggenheim Museum ha compilado una selección de obras innovadoras de 40 artistas de 13 países latinoamericanos, en el marco del proyecto Guggenheim de elaborar una cartografía universal de arte ("UBS MAP Global Art Initiative", co-financiado por el banco suizo UBS). Reflexiones sobre prácticas de arte contemporáneas ${ }^{1}$, apoyan, en primer lugar, el cambio paradigmático de una orientación nacional de museos y coleccionistas latinoamericanos a una orientación transnacional o "transareal" (ETTE, 2008: 17). Tan sólo la población de los US Latinos (más de 60 millones) apunta a una nueva constelación transcultural que requiere acercar la producción y recepción artísticas a los espacios, dinamismos y redes móviles en el continente latinoamericano actual. El enclave latino de Miami desempeńa un papel vital en el proceso transcultural hemisférico y en el fomento del nuevo boom del arte latinoamericano, como veremos más adelante.

El proyecto Bajo el mismo sol reorganiza e integra también a los artistas migrados que no formaban parte de las historias del arte nacionales. La iniciativa retoma proyectos panamericanos como el del chileno-americano Juan Downey (1940-1993), Video Trans Americas de 1976 (hoy integrado en la colección del MoMA). El artista conecta las regiones latinoamericanas favoreciendo su visibilidad mutua, viajando en un minibús y filmando un pueblo que le muestra en vídeo al próximo pueblo, en una especie de estafeta itinerante.

Pablo León de la Barra publicó un ensayo sobre el proyecto de la cartografía global de arte, en el que afirma la directriz integradora:

\footnotetext{
1 "Aimed at generating a dynamic engagement with artists, curators, and a general audience, the Guggenheim UBS MAP Global Art Initiative seeks to foster intercultural exchange through acquisitions for the Guggenheim's collection, international touring exhibitions, and far-reaching educational and online activities." (Disponible en: <https://www.guggenheim.org/news/ guggenheim-announces-map-curator-for-latin-america>. accesado en: 15 jan. 2016.
} 
Bajo un mismo sol y la Guggenheim UBS MAP Global Art Initiative no sólo pretenden incorporar la obra de artistas y regiones a los cánones de los que han sido previamente excluidos; también posicionan la obra de arte y el museo como cajas de herramientas, como lentes y amplificadores con el poder de cambiar las maneras en que vemos y nos relacionamos con el resto del mundo. (LEÓN DE LA BARRA, 2013) ${ }^{2}$

The Cisneros Fontanals Art Foundation (CIFO) fue fundada por Ella Cisneros Fontanals en 2002 con una colección que reúne a artistas de todo el continente. Esta institución organiza exposiciones internacionales en EE.UU., Europa y América Latina y, hasta ahora, ha apoyado a más de cien artistas. Desde Miami y con sede en Madrid, avivó la escena de arte latinoamericano por su orientación de coleccionista continental y transnacional, contribuyendo, además, sustanciosamente a la construcción del museo de arte de Miami por los arquitectos Herzog \& De Meuron y donando obras para exponerlas allí públicamente. Recientemente, Ella Fontanals Cisneros transfirió su domicilio principal a La Habana porque, según sus palabras ${ }^{3}$, hacía falta apoyar la escena de arte local, cuando en Miami ya iba marchando todo viento en popa. La perspectiva transnacional se debe en parte a su propia biografía, marcada por itinerancias con varios domicilios y cambiantes negocios, tras nacer en Cuba y haber crecido en Venezuela.

Será interesante observar las consecuencias de la flexibilización del embargo en la Isla (que la coleccionista ha evitado operando desde la sede en Madrid). Ella Cisneros Fontanals compró el Archivo Veigas de materiales relacionados con el arte contemporáneo cubano y desea hacerlo accesible en línea para todo el mundo. Además de este propósito de integración participativa, quiere apoyar exposiciones en la Isla de artistas que a menudo suelen trabajar en condiciones precarias. Los próximos proyectos de la muy activa coleccionista giran en torno a la apertura de una biblioteca de arte y una sala de exposiciones (FONTANALS-CINSEROS, 2014).

Igualmente la Colección privada suiza Daros (propiedad de la familia Schmidheiny) dispone de la mayor biblioteca de Europa sobre arte latinoamericano contemporáneo, en su sede de Zúrich. Al contrario de las colecciones en América Latina, más bien limitadas al ámbito nacional, la biblioteca abarca más de 8.500 monografías y catálogos de exposiciones, libros y estudios sobre el arte del continente íntegro y es, por tanto, única.

\footnotetext{
${ }^{2}$ En la misma página web, se halla un vídeo de unos siete minutos, en el que el curador explica muy bien el concepto.

${ }^{3}$ Fue lo que me dijo al coincidir en una jornada (el UBS Art Forum en Wolfsberg) sobre el arte latinoamericano en el mundo, titulado "A New Frontier: Contemporary Art from Latin America", el 27 y 28 de octubre de 2014.
} 
Además de este singular tesoro, la propia Colección Daros Latinamerica ${ }^{4}$ incluye más de 1.200 obras de 120 artistas y de todos los géneros de los últimos sesenta ańos, figurando, así, entre las más amplias del continente. En su sede en Rio de Janeiro, la Casa Daros organizó en pocos años una serie de veinte exposiciones; desafortunadamente cerró sus puertas a finales de 2015. En el futuro, los propietarios se concentrarán en las cooperaciones con museos en todo el mundo con préstamos, abriendo, así, paso a la itinerancia transnacional y distribución global de las obras.

Sin duda, las tres instituciones presentadas, influyen profundamente en la producción y el fomento artísticos contemporáneos de América Latina, desde Europa, desde Nueva York y desde Miami. Sus poderosas iniciativas no sólo ayudan a descubrir siempre nuevas obras de arte latinoamericano, sino que atraen a artistas y despiertan el interés de coleccionistas nacionales e internacionales. Habrá que ver si el impulso se sigue afianzando, a pesar del estancamiento económico por el que están pasando los países emergentes.

Las dos colecciones privadas abarcan artistas de todas las regiones del continente y de todas las edades, los muy famosos pero también los "jóvenes". No hay tantas coincidencias como se esperaría, sin embargo, están representadas en ambas colecciones, por ejemplo, Tania Bruguera, Doris Salcedo, Milena Bonilla, Rosângela Rennó u Óscar Muñoz. La gama de generaciones en la colección Daros abarca los nacidos a lo largo de todo el siglo XX, el artista mayor es el uruguayo Carmelo Arden Quin (1913-2010), uno de los pocos ya fallecidos, frente al menor Javier Castro (1984, La Habana); entre las mujeres la línea generacional va de Teresa Serrano (1936, México D.F.), Doris Salcedo (1958, Bogotá) a Milena Bonilla (1975, Bogotá). ${ }^{5}$

El vídeo del cubano Javier Castro, el benjamín de la colección Daros, mostrado en la exposición de la Casa Daros, Cuba - Ficción y Fantasía (2015) (CASTRO \& GÁRCIGA, 2007), cala el puente hacia la colección de dientes literarios de Valeria Luiselli (1983), una de las escritoras más jóvenes y talentosas de la actualidad latinoamericana, que representa una generación dada a la movilidad, al nomadismo transnacional. Su libro La historia de mis dientes (LUISELLI, 2013) entregado al campo metafórico de las mordidas literarias podría relacionarse, por un lado, con el movimiento estético de la antropofagia de los años 20 en Brasil. Por el otro, el hambre y la sed del interés exotista de Occidente por la literatura y el arte latinoamericanos muestran la oposición de parámetros estéticos locales vs. los extranjeros, en constelaciones hegemónicas de Norte-Sur. Aunque englobaría seguramente estímu-

\footnotetext{
${ }^{4}$ Ver la página web de la Colección: <http://www.daros-latinamerica.net/collection>. Acceso en: 15 jan. 2016.

${ }^{5}$ Cf. <http://www.daros-latinamerica.net/artworks>. Acceso en: 15 jan. 2016.
} 
los inspiradores también, la metáfora de los dientes tendrá que ceder, en este artículo, a la más blanda de las burbujas.

\section{Las Letras}

En el campo de la literatura, en principio, el Boom seguía en pie, hasta que murieran los maestros de la generación (Julio Cortázar en 1984, Carlos Fuentes en 2012 y Gabriel García Márquez en 2014). Aún hoy vive el mito de estas estrellas surgidas en los años 60, y se venden sus libros; de hecho, el mercado no se hunde, también gracias a ellos. ${ }^{6} \mathrm{Al}$ último sobreviviente del cuarteto central del Boom, Mario Vargas Llosa, se le trata como a una celebridad, fue ennoblecido por la Academia de Suecia y por el Rey de España, y cada libro que sale de él es acogido con un enorme interés mundial. Las generaciones posteriores no han logrado estar a las alturas en cuanto al grado de notoriedad.

En el caso del mercado del libro, nunca ha surgido la discusión que hoy causan los excesos mercantiles en el ámbito de las artes visuales y que cualquier boom suscita. Nunca nadie preguntaba si el Boom de la narrativa latinoamericana, hecho en España, amenazaba con resultar en una burbuja o no, aunque fuera un mercado potente, al haber vendido Gabriel García Márquez 30 millones de ejemplares tan sólo de su novela Cien años de soledad.

España, por demanda de un país bajo el pulgar de la dictadura y censura, además exento de una escena literaria digna de mención, transfirió su producción al Nuevo Mundo. Se proyectaron las expectativas en una serie de escritores emergentes dados a la experimentación literaria, creadores de la poética de lo real maravilloso o del realismo mágico, y relacionados con impulsos políticos de la Revolución cubana.

El proyecto de las agentes peninsulares, en particular, Carmen Balcells, y de la industria editorial, especialmente Carlos Barral, se tornó en éxito rotundo y en esplendor inesperado. El auge del Boom (con mayúscula) e impacto global se mantuvieron durante unas dos décadas, en sentido estricto, aunque los maestros siguieron publicando y creando un sustrato para futuras generaciones y fases de la producción literaria: el post-Boom, luego, en 1996, McOndo (en el cono sur) y Crack (en México), novelistas sueltos y las novelistas (Elena Poniatowska, Cristina Peri Rossi o Luisa Valenzuela), hasta las tendencias actuales. El éxito persistente de los del Boom también echó sombras y, según la recepción externa, los literatos de hoy tienen que seguir

\footnotetext{
${ }^{6} \mathrm{Al}$ lado de los cuatro titanes, hay toda una serie de autores sincronizados, igualmente renombrados, innovadores, que hacían época: Juan Carlos Onetti, Alejo Carpentier, Juan Rulfo, José Donoso, Augusto Roa Bastos, Joáo Guimarães Rosa, etc.
} 
midiéndose con Gabo y su alegoría macondina (MURRENHOFF, 2104), ${ }^{7}$ por ejemplo. A pesar de los intentos numerosos de liberarse los autores del lastre del culto a los maestros en la creación literaria, los lectores extranjeros sí siguen practicando, exigiendo y con ello perpetuando procesos de canonización en un círculo reducido y selecto de literatura universal. Así, se mantienen tercamente, aunque los momentos estelares del realismo mágico empiecen a mirarse con nostalgia y estén extinguiéndose paulatinamente. Quizás, Isabel Allende haya contribuido a tal agotamiento, exprimiendo el limón hasta lo último.

El perseguido relevo en las fases tercera y cuarta, después del cuarteto de los grandes y del post-Boom, resultó en un puñado de autores individuales de novelas muy importantes, internacionalmente reconocidas con una escritura que cubre espacios narrativos transnacionales, nómadas: uno, Roberto Bolaño quien ya murió (entre México, España y Chile), Jorge Volpi (entre Alemania y México), Zoé Valdés o Guadalupe Nettel (entre París y Cuba o México) y Laura Restrepo (entre España, México y Colombia). Tanto entre los nacidos en los años 40 como en los 50, hay escritoras y escritores renombrados, ${ }^{8}$ que, sin embargo, no llegan a crear más demanda. El hecho de que, a diferencia de los autores del Boom, no hayan creado escuela, forma, en cierta medida, parte de su programa estético. Así pues, Roberto Bolaño, afirmó la necesidad de "meterse por estructuras propias" ante la imposibilidad de seguir los pasos marcados por las estructuras creadas por los autores del Boom (BOLAÑO, 1999).

El Crack y el post-post-Boom fueron encaminados por una generación que confiaba poco en el futuro, nacida en los 70, socializada en la violencia, las crisis económicas y el estancamiento político. Su diversidad poética y anti-exotista, sobria, pragmática, concisa, se expresa, por ejemplo, en una antología del género corto, de cuentos, titulada El futuro no es nuestro (2009) y compilada por el autor peruano Autor Diego Trelles Paz (BOLAÑO, 1999). Los autores de dicha generación son (como Bolaño) nómadas, transnacionales, desterritorializados, o como lo expresara Ottmar Ette, están "sin domicilio fijo", no radicados necesariamente en sus patrias sino escribiendo desde el extranjero, por ejemplo, Santiago Roncagliolo (1975, Perú), Andrés Neumann (1977, Argentina) o Yuri Herrera (1970 México).

Ya hemos entrado en pleno siglo XXI, y con escritoras como Valeria Luiselli, nos movemos hacia una quinta fase después del Boom. Luiselli tiene una proyección admirable y un gran futuro por delante. Experimenta, en el

\footnotetext{
${ }^{7}$ Muchos literatos han intentado romper con el realismo mágico, no sólo los de McOndo y Crack. ${ }^{8}$ Por ejemplo, César Aira (1949), Ricardo Piglia (1941) Diamela Eltit (1949); Sergio Chejfec (1956), Carmen Boullosa (1954) y Horacio Castellanos Moya (1957).
} 
nivel discursivo de sus textos, con el mismo modelo transcultural, que hemos visto en su biografía y en los espacios y tiempos. Por un lado es sumamente intertextual tejiendo una red densa de referencias a tantos textos interconectados. Las relaciones complejas y dinámicas de redes y vínculos, de nodos rizomáticos, se crean en las dimensiones de ficcionalidad, de espacio y tiempo y de género. Además se incorporan en los tejidos de una literatura globalizada.

Hoy en día, ya no hablamos de la literatura latinoamericana y sus escuelas y movimientos sino de literatos hispanoamericanos. Ya no hay boom en el continente porque las relaciones geográficas fijas no les interesan a los nuevos autores. Ya no les apetece identificarse mediante sus pasaportes.

Sin embargo, sobresale una modalidad narrativa en las fases posteriores al Boom que merecería ser llamado un género literario, ya que, particularmente en América Latina, ha tenido un auge especial: el microrrelato. Siempre ha existido la minificción, también en el área hispánica, en variantes dispersas, pero nunca sistemáticamente coordinadas ni por el lado de la producción ni por el de la recepción. Eso sí, pueden considerarse como decisivos precursores del actual microrrelato los autores del modernismo y la vanguardia (Rubén Darío, Vicente Huidobro, Julio Torri o Leopoldo Lugones), más adelante, en el Boom y alrededores, Jorge Luis Borges o Julio Cortázar, Juan José Arreola. Pero es a partir del 'dinosaurio' de Augusto Monterroso de 1959, y también de 1977 cuando José Emilio Pacheco acuñara el término "microrrelato" en sus Inventarios que se establece el microrrelato como modalidad propia, de especial concentración en América Latina. El otro motor fue la recepción con los críticos y antólogos pioneros de mediados de los años 90, a saber, Irene Andres-Suárez, Fernando Valls, David Lagmanovich, Pedro de Miguel, Ana María Shúa, Francisca Noguerol, Lauro Zavala, entre otros, y los propios autores de minicuentos.

En el siglo XXI, el género recibió un impulso adicional a través del giro en los canales de distribución. Mientras que las editoriales han empezado a publicar tiradas modestas de novelas impresas, y el mercado del libro ha tambaleado, la conexión por diferentes redes a través de los nuevos medios sociales y los blogs ha fomentado el formato de la minificción, concentrados narrativos de un par de líneas, que caben en una pantalla, elípticos y a menudo de humor o fina y concisa ironía.

Tras el neobarroco de Alejo Carpentier, el segundo neobarroco de Severo Sarduy y Néstor Perlongher de la fase post-Boom podría detectarse asimismo como una poética específica aunque no exclusiva de América Latina. ${ }^{?}$

\footnotetext{
${ }^{9}$ A la literatura de los US Latinos actual y de las pasadas décadas también se le podría adscribir cierta unidad, por lo menos a nivel temático.
} 
Las tendencias más recientes, aunque de difusión todavía menor, serían el transrealismo poético, o la generación mutante de Colombia, con Santiago Gamboa, Fernando Vallejo y Laura Restrepo. El narcotráfico, en tanto que actividad transareal (abarca múltiples esferas socioeconómicas, políticas) se refleja en la narconovela, a su vez, subgénero que se puede encontrar más allá de cualquier frontera nacional.

No sólo tenemos que enfrentarnos con una diversidad temática y discursiva de la literatura continental, en el siglo XXI, sino con un fragmentarismo (casi laberíntico) del mercado del libro que además suele restringirse a menudo a los límites nacionales de edición. Apenas se difunden al exterior de cada país, es decir, que falta la circulación en "sistemas de distribución a nivel continental” (GUERRERO, 2009: 25). Jorge Volpi deploró este hecho hace ya diez años: "Los lectores de cada país apenas conocen a los escritores de los otros". Por ello, apenas se nos permite ya echar miradas panorámicas o sinópticas, aglutinadoras a una literatura latinoamericana exenta de homogeneidad (VOLPI, 2006: 61). ${ }^{10}$

En definitiva, se repite la situación de las artes visuales de hace cincuenta años, que causó la ausencia del coleccionismo continental, panamericano en museos y bibliotecas de arte, ya que sólo se daba en Europa y EE.UU. En el siglo XXI, las artes visuales latinoamericanas acabaron convirtiéndose en marca. Habrá que ver, hasta qué punto los canales de difusión en línea, las bibliotecas virtuales de creación y crítica o los blogs lograrán compensar la falta de integración actual y el desinterés por las letras entre países vecinos del continente.

En cuanto al mercado, los radios de acción de los grandes conglomerados editoriales parecen cada vez más descontrolados, un bosque impenetrable de editoras reunidas básicamente en tres grupos desde marzo de 2014: Planeta/Santillana, Sudamericana (y, en Colombia, Norma) ${ }^{11}$. Las editoriales españolas están asentadas sólo en pocos países hispanoamericanos: Penguin/Random House y Alfaguara juntos, por ejemplo, tienen sucursales en Argentina, Uruguay, Chile Colombia, Perú y México. ${ }^{12}$ Además, cabe tener en cuenta el buen trecho que hay entre la producción bastante copiosa

\footnotetext{
${ }^{10}$ Gustavo Guerrero cita los ensayos de tres literatos que dudan de la posibilidad de abarcar el continente entero: Carlos Cortés, "La literatura latinoamericana (ya) no existe" (1999); Jorge Volpi, "El fin de la narrativa latinoamericana" (2004); y Jorge Fornet, "Y finalmente, ¿existe una literatura latinoamericana?” (2007) (GUERRERO, 2009: 26).

${ }^{11}$ Para mayor información remito al estudio de Carlos Moneta. "España y la industria editorial en Argentina y América Latina en la próxima década: ¿competencia o cooperación?” (MONETA, 2009).

${ }^{12}$ Algunas iniciativas menores de estas editoriales, como la de lanzar al mercado editorial a diez autores latinoamericanos poco conocidos por año, son meritorias pero no cambiarán el gran panorama. Cf. Alberto Gordo. Un mapa para leer a América Latina” (GORDO, 2015).
} 
de los libros ${ }^{13}$ y su distribución y lectura, asimismo entre el mercado de masas y el nicho minoritario.

\section{Corrientes contrarias en las letras y las artes}

No ha habido otro grupo de literatos ni cercanamente tan exitosos como los de los años 60 y 70. El interés por la literatura latinoamericana, por ejemplo, en el área germanoparlante, ha disminuido considerablemente desde entonces; las editoriales, entre ellas Suhrkamp, publican ya solo pocos títulos por año. ${ }^{14}$

Este estancamiento contrasta con la creciente demanda internacional de arte latinoamericano. El auge de las artes visuales en el mercado global, junto con la explosión de precios, ha invitado al arte latinoamericano a subir a bordo, a convertirse de nicho frente a EE.UU. y Europa en socio influyente. Sin duda, fue la feria de arte más importante del continente, Art Basel Miami, la que facilitó este proceso obrando como puente entre las dos Américas e integrando América Latina en el circuito global. De un total de 260 galerías del mundo entero que se presentan en la feria glamorosa, 26 vienen de México y Brasil, seguidas de las chilenas, peruanas y colombianas (GAMERMAN, 2011).

Pero ya que cualquier mercado puede ser cíclico, el recién nacido interés suscita inmediatamente cierto escepticismo respecto a la solidez de tal demanda y su beneficio comercial a largo plazo. La otra cara de la medalla se expresa en la aliteración usada en el título: ¿Đoom o burbuja? Esta metáfora económica ha cobrado un nuevo protagonismo desde la crisis financiera de 2008. La especulación en el mercado mundial de arte es un hecho: precios exuberantes, subidos en espiral hacia altitudes inusitadas, las cuales, según afirman los propios artistas, no tienen nada que ver con la relevancia y el valor intrínseco de sus obras. ${ }^{15}$

\footnotetext{
13 "Entre 2004 y 2005, por ejemplo, su caudal crece en más de un $25 \%$ y pasa, en la sola América Latina, de 11.466 a 14.351 títulos, sin que se haya de descontar más de un 15\% de traducciones." (GUERRERO, 2009: 25).

${ }^{14}$ Mientras los pesimistas evocan el estallido de las burbujas literarias con pérdidas sustanciosas de un $40 \%$ de su facturación, (lo que impide a los autores vivir de su oficio, cf. Josep Massot, "El arte no paga" (MASSOT, 2014), hay también afirmaciones más optimistas que lanzan a nuevos escritores latinoamericanos, entre ellos César Aira, Ricardo Piglia, Mario Bellatin, Rodrigo Rey Rosa, Rodrigo Fresán o Álvaro Enrigue. Cf. Richard Kämmerlings. "Lateinamerika ist wieder da" (KÄMMERLINGS, 2015).

${ }^{15}$ Así, el artista Gerhard Richter, cuya obra se vende por precios récord, los más altos de Europa, ya lo dijo en 2005 y lo sigue repitiendo: "Und das tun sie ja nun tatsächlich: allgemein viel zu viel für Kunst zahlen. Da besteht doch ein völliges Missverhältnis zwischen dem Wert und der Relevanz von Kunst und diesen wahnwitzigen Preisen, die dafür gezahlt werden" (RICHTER, 2005). Se encuentran afirmaciones parecidas en otra entrevista a Richter por Hanno Rauterberg, "Es geht nur noch um den Preis" (RICHTER, 2015).
} 
Para el estallido de la burbuja no hay explicaciones claras, y muchas son irracionales. Estallan cuando hay excesiva confianza, optimismo, escasean los compradores y caen los precios. El porqué de estos mecanismos no se ha podido dilucidar porque incluso surgen burbujas sin especulación, excesiva confianza, precios desmesurados u objetos sobrevalorados (KINDLEBERGER, 2005 [1978]).

La periodista de la Financial Times, Georgina Adam, especializada en el mercado global de arte, en su libro (ADAM, 2014a), expresa dudas no sólo respecto a la opacidad de los negocios como terreno fértil de lavado de dinero y evasión de impuestos, sino también con respecto al boom.

Everyone wants to know whether this market is a bubble and, if so, when it will burst? This seems unlikely to happen any time soon: the sheer amount of global wealth; the massive museum-building programmes; the positioning of art as an element of the celebrity and fashion worlds, and the seductive lifestyle the art world offers are all very attractive to the super-rich. (ADAMS, 2014b)

La metáfora de la burbuja ha inspirado muchos procesos, no sólo los económicos, también los culturales y los artísticos. En vez del peligro económico del estallido de burbujas, Guillermo Cabrera Infante, con su habitual cinismo, usó la metáfora en el terreno de la debilidad o ingravidez de la poética de sus colegas del Boom, meras burbujas que no dejan mayor rastro. Se trata del reproche de que sólo fuera un movimiento publicitario de agentes y editores espańoles, que el Boom fue un "estallido de una pompa de jabón perfectamente ingrávida sin mayores consecuencias." ${ }^{16}$ Antonio Machado, en cambio, vio precisamente en la corta duración y creación ligera, efímera, imprevista, transitoria, sin consistencia sólida cualidades a perseguir. Eligió la burbuja como metáfora de su poética, en la primera mitad del siglo XX, al afirmar que no buscaba dejar rastro de gloria (póstuma) con su poesía. ${ }^{17}$

\section{La metáfora polivalente de la burbuja}

Después de presentar un esquemático inventario de las artes y letras en América Latina de hoy y los pasados cincuenta años, quisiéramos aportar dos

\footnotetext{
${ }^{16}$ Citado en: Adlai Stevenson Samper. "Carlos Fuentes, en su región más transparente”. El Heraldo del 28 de enero de 2012. Disponible en: <http://www.elheraldo.co/entretenimiento/cultura/carlosfuentes-en-su-region-mas-transparente-54979>. Acceso en: $15 \mathrm{dez} .2015$.

17 “CXXXVI". Proverbios y Cantares I. (MACHADO, 2015). "Nunca persegui la gloria ni dejar en la memoria / de los hombres mi canción; / yo amo los mundos sutiles, ingrávidos y gentiles I como pompas de jabón. / Me gusta verlos pintarse Ide sol y grana, volar / bajo el cielo azul, temblar súbitamente y quebrarse." La burbuja sirve igualmente para metaforizar el acto de redactar la primera página de una novela, aunque la mayoría de estas primeras frases "no eran precisamente burbujas conteniendo buenas novelas, sino meras y disuasorias pompas de jabón” (APARICIO MAYDEU, 2014).
} 
ejemplos concretos de las obras de dos artistas contemporáneas y explicar el valor de esta metáfora polivalente, más allá de su uso inflacionista en asuntos económicos. Quisiéramos mostrar que las burbujas ingrávidas no sólo ayudan a explicar configuraciones artísticas sino también las socioculturales y políticas en América Latina. Podríamos simbolizar el fenómeno del contacto cultural en contextos de migración y diáspora mediante la unión de dos burbujas.

Arrancaremos con un ejemplo de las artes visuales que muestra la fuerza y el peso de la metáfora. Como símbolo de la fugacidad de la vida, como memento mori, el juego de niños de las pompas de jabón crea una paradoja. La artista mexicana Teresa Margolles (1963) agudiza esta paradoja entre belleza iridiscente y mortalidad, incluso brutalidad, en su instalación "En el aire" (2003) presentada en su primera exposición individual en Alemania. Máquinas producen y lanzan burbujas al aire, en una sala de museo. Hasta aquí, todo perfecto. El espectador se asustará o incomodará, en cambio, cuando lea la ficha técnica de la obra, donde se le advierte que el agua residual utilizada para las burbujas procede de la morgue, que se había aplicado para lavar cadáveres asesinados, antes de la autopsia ("Bubbles made from water from the morgue that was used to wash corpses before autopsy").

El agua reciclada fue desinfectada, claro, sin embargo, el contacto de las pompas de jabón con nuestro cuerpo se torna en algo más allá de un simple recuerdo de la naturaleza transitoria de nuestras vidas. Flotan en el aire primero festiva y lúdicamente, ingrávidos, tornasolados, de diversos tamaños, cuando, de repente, se estallan contra nuestro cuerpo y nos salpican levemente (MARTÍNEZ Y MARTÍNEZ, 2011: 58). Las burbujas como símbolos de un una persona asesinada, una vida destruida, en el contexto de la violencia mexicana, causan sin duda un choc en los espectadores.

Las formas redondas perfectas de belleza etérea se convierten en repulsivas, en el momento de estallar en el suelo del museo o en los vestidos o la piel de los visitantes.

Through death, an object once beautiful and desirable becomes repulsive. As a traditional symbol of Vanitas and pictorial realisation of the "homo bulla", the soap bubble takes a drastic turn in Margolles' installation. The life of the cleansed body already "burst" - under violent circumstances. [...] Like a horrifying return from death, the bubbles serve as reminders of life destroyed; [...]." (KITTELMANN \& GÖRNER, 2004: 42)

The moment of naive pleasure turns into one of knowing repulsion: [...] It's unimportant that the water is disinfected; the stigma of death turns the beautiful into the horrific [...]. Margolles originally comes from Culiacán, a town scarred by the drug trade, a place where many people die violently and young. [...] Margolles, who works only with the bodies of those that suffered a violent death, wants to rescue them from invisibility [...] The artist herself is 
clearly haunted by the production of these works. They are not a catharsis for the poverty and violence she witnesses; they are the production of mourning. [...] Margolles suffers from acute grief for her country. At her own avowal it would be impossible to make representative images to describe her reality; it would simply be too appalling. (COULSON, 2004)

Las burbujas reproducen indirectamente y metaforizan todo el entorno violento mexicano.

Las implicaciones sociales, espaciales y filosóficas de las pompas de jabón las analiza Peter Sloterdjik, en su trilogía Esferas (SLOTERDIJK, 2003, 2004, 2006), en el contexto de la globalización.

Los cambios en la percepción espacial, el repensar del espacio como transnacional y transareal en un mundo de movilidad y migraciones, pueden visualizarse provechosamente a través de las metáforas analizadas por Sloterdjik en su teoría esferológica. El filósofo alemán parte del espacio de la placenta prenatal en el vientre materno y metaforiza, en la burbuja, no solo un entorno creacional, sino el individuo propiamente dicho. Las burbujas pueden formar un conjunto, la espuma, ser globos o esferas.

Las ingrávidas burbujas apuntan a espacios importantes para procesos culturales, "de los que la física no sabe nada." (SLOTERDIJK, 2006: 529). El interior vacío (con sólo un poco de aire), la ausencia de espacio, los proyectó Hermann Broch en el ser humano, al afirmar que "el hombre sin espacio es un ser ingrávido" (MONTFORT, 2011). La metáfora de la burbuja muestra, en este contexto, su particular cercanía con el "hombre sin contenido" retratado por Giorgio Agamben en 1970, para el cual la figura del artista es paradigmática. Pero la senda filosófica nos lleva, además, hacia lo que Slavoj Žižek ha constatado como el "sujeto vacío" desde el pensamiento cartesiano, pasando por el idealismo alemán hasta las teorías del inconsciente según Freud y Lacan: "El sujeto freudiano es vacío y mecánico". ${ }^{18}$

En su artículo sobre las tres principales metáforas redefinidoras del espacio de Sloterdijk, Juan Edilberto Rendón Ángel da un resumen útil:

[...] la espuma, como informe aglomeración de burbujas, es la metáfora que, a partir del desamparo que generó la desintegración del gran globo, propone una esferología plural o una multiplicidad de espacios que ya no se preocupan por el centro, sino más bien en, sin perder la posibilidad de entrar en contacto unos con otros, construir sus propias cubiertas autoprotectoras y apostarle a la ligereza frente a la obsesión por la gravedad, el peso y el centro que perdió al globo (RENDÓN ÁNGEL, 2011).

\footnotetext{
${ }^{18}$ Cf. la entrevista en el programa Sternstunden Philosophie del 17 de mayo de 2009. Disponible en: <http://goo.gl/bBk8Co>. Acceso en: 16 jan. 2016.
} 
Rendón subraya, además, la provisionalidad y pluralidad de la espuma (y del espacio), la ligereza expansiva, transitoria, frágil e íntima de las membranas de la burbuja, al lado de las vinculaciones englobantes de la metáfora de orden superior, la esfera. Es bastante común que las metáforas elegidas, también la burbuja, se muestren atravesando las dimensiones cósmicas, desde las micro- hasta las macro-esferas. Así, una reseñista del libro de cuentos de Carlos Ollero, Como pompas de jabón (2013), compara los relatos lúdicos (con minicuentos y poemas), historias efímeras (y los encuentros y desencuentros de sus personajes) con las burbujas y éstas con "pequeños planetas independientes que no saben cuánto tienen en común. Se cruzan, se separan, se alejan y vuelven caprichosamente al ritmo que marcan el aire y el azar." (ALGARRA, 2014).

Valeria Luiselli, en sus obras, Papeles falsos y Los ingrávidos, trabaja con un discurso fragmentario, caleidoscópico, espumoso: "[...] ha erigido su obra en base a esa ausencia de un centro geográfico-vital: tanto en los ensayos del primer libro como en la narración del segundo, el nexo parece ser el desarraigo contemporáneo y la lúcida y fantasmal 'ingravidez' que se desprende de él." (MATTIO, 2013). En su novela Los ingrávidos, evoca, además, la fugacidad y la desaparición física y en parte moral. ${ }^{19}$ El desmembramiento en "estructuras nodulares”, abiertas y fluidas, nunca jerárquicas (MONTFORD, 2011), se refleja en el fragmentarismo discursivo de la novela compuesta de notas de post-it. Luiselli compone un homenaje al escritor mexicano Gilberto Owen quien precisamente escribió, en 1921, un precioso poema titulado "La pompa de jabón” que contiene in nuce (o in bulla) toda la ingravidez de la novela de Luiselli. "Aquel rostro, aquel libro, aquel paisaje, / y todo el iris y yo mismo, todo, / todo en tu agua sedienta / de imágenes." Esta sed de visualización metafórica parte de la propia burbuja. El agua será el punto de referencia de todo el poema. Owen compara las burbujas con los ríos que fluyen por un cauce airoso, asimismo con las lágrimas, "rocío amargo y trémulo", y finalmente con la vida "tránsfuga" (OWEN, 2006: 71).

La paradoja entre el juego de niños de las pompas de jabón y una atmósfera (latente o explícita) de muerte y violencia, mostradas paratextualmente con una foto de dos ataúdes en la cubierta, se presenta como motivo literario en la novela La transmigración de los cuerpos, del arriba mencionado autor mexicano, Yuri Herrera. Se nos narra la escena de un vendedor ambulante de autobús quien ofrece el inofensivo jueguito de las burbujas (MORELLA, 2013).

Para terminar, he aquí otro quiasmo en el nivel metafórico: aunque la esfera hueca de una capa de líquido (con dos películas finas de jabón y agua)

\footnotetext{
${ }^{19}$ Valeria Luiselli: "También yo quería escribir una novela sobre las personas que tienen cierta ingravidez moral.” (CORTÉS KOLOFFON, 2011).
} 
dura sólo pocos segundos y luego estalla en el aire o por el contacto con un objeto duro (WIKIPEDIA, 2016), dispone de una proyección metafórica fuertísima, polifacética y sólida que resistirá a dinamismo globalizantes. Al contrario, el concepto del boom, menos plástico, sino de etimología onomatopéyica, genera mucho ruido (la burbuja explota silenciosamente), pero se limita a significar simplemente eclosión o crecimiento repentino en importancia y popularidad, o periodo de prosperidad y progreso. Por ende, se reduce a un peso metafórico más bien recesivo. Los extremos dicotómicos del boom y la burbuja resultan poco productivos y solicitan sustituir tal bipolaridad por dialécticas más moderadas, también en ámbito artístico.

\section{Referencias bibliográficas}

ADAM, Georgina. Big Bucks: The Explosion of the Art Market in the 21st Century. London: Lund Humphries, 2014.

"How long can the art market boom?", Financial Times, 6 jun. 2014. Disponible en: <http://www.ft.com/intl/cms/s/2/9f4fff3c-eb27-11e3-bab600144feabdc0.html>. Acceso en: 15 jan. 2016.

ALGARRA, Núria. „Como pompas de jabón, de Carlos Ollero“, La Estantería de Núria (Blog), 26 jan. 2014. Disponible en: <https://laestanteriadenuria. com/2014/01/26/como-pompas-de-jabon-de-carlos-ollero/>. Acceso en: 17 jan. 2016.

APARICIO MAYDEU, Javier. „Aprendí de Gabo“, El País Babelia, 11 set. 2014. Disponible en: <http://cultura.elpais.com/cultura/2014/09/03/ babelia/1409738109_787119.html>. Acceso en: 17 jan. 2016.

BOLAÑO, Roberto, „La beleza de pensar“. [1999]. Santiago de Chile: UC Televisión. Entrevista concedida a Cristián Warnken. Disponible en: <https://www. youtube.com/watch?v=NPL3O1UL3-E >. Acceso en: 15 jan. 2016.

CASTRO, Javier \& GÁRCIGA, Luis. Más allá de las luces que veo. [Filme-vídeo]. Producción de Javier Castro y Luis Gárciga. Zúrich: Colección Daros, 2007. 1:15 mins, color.

COULSON, Amanda."Teresa Margolles: Museum für Moderne Kunst, Frankfurt Germany”, Frieze Magazine, n. 85, set. 2004.

ETTE, Ottmar. „Caminos hacia una filología transareal.“ In: HAASE, Jenny; REINSTÄDLER, Janett \& SCHLÜNDER, Susanne (Ed.). El andar tierras, deseos y memorias: homenaje a Dieter Ingenschay. Madrid; Frankfurt; Main: Iberoamericana; Vervuert, 2008: 17-31.

FONTANALS-CISNEROS, Ella. „Es bueno para todos que el embargo termine', dice la coleccionista Ella Fontanals-Cisneros", Diaro de Cuba, 19 out. 2014. Disponible en: <http://www.diariodecuba.com/cultura/1413746710_10876. html>. Acceso en: 15 jan. 2016).

GAMERMAN, Ellen. "Art Basel Looks South", The Wall Street Journal, 25 nov. 2011. Disponible en: <http://goo.gl/Z55VeH>. Acceso en: 18 jan. 2016. 
GORDO, Alberto. „Un mapa para leer a América Latina“, El Cultural, 5 jun. 2015. Disponible en: <http://www.elcultural.com/noticias/letras/Un-mapa-para-leera-America-Latina/7885>. Acceso en: 15 jan. 2016.

GUERRERO, Gustavo. „La desbandada. O por qué ya no existe la literatura latinoamericana“, Letras Libres, jun. 2009: 24-28.

HERRERA, Yuri. La transmigración de los cuerpos. Madrid: Periférica, 2013.

KÄMMERLINGS, Richard. „Lateinamerika ist wieder da“, Tages-Anzeiger, 23 abr. 2015. Disponible en: <http://goo.gl/NOKOXF>. Acceso en: 15 jan. 2016.

KINDleberger, Charles P. Manias, Panics, and Crashes: A History of Financial Crises. 5. ed. New York: Wiley, 2005.

KITTELMANN, Udo \& GÖRNER, Klaus. Muerte sin fin. Frankfurt am Main: Hatje Cantz Verlag, 2004.

LEÓN DE LA BARRA, Pablo. „Bajo un mismo sol: arte de Latinoamérica hoy“. Guggenheim Foundation, 2013. Disponible en: https://goo.gl/aDY $\underline{4 P 4}$. Acceso en: 15 jan. 2016.

LUISELLI, Valeria. La historia de mis dientes. México: sextopiso, 2013.

CORTÉS KOLOFFON, Adriana. „La escritura caleidoscópica de Valeria Luiselli“, Siempre! (México), 27 ago. 2011. Disponible en: <http://www.siempre.com. mx/2011/08/la-escritura-caleidoscopica-de-valeria-luiselli/>.. Acceso en: 15 dez. 2015.

MACHADO, Antonio. „CXXXVI: Proverbios y Cantares - I”. Disponible en: <http:// www.armandfbaker.com/translations/castile/proverbs_CXXXVI.pdf>. Acceso en: 15 dez. 2015.

MARGOLLES, Teresa. En el aire (In the Air), 2003. Disponible en: <http://goo.gl/ RLGQDh>. Acceso en: 16 jan. 2016.

MARTÍNEZ Y MARTÍNEZ, Gabriela. De la violencia a la cruel espectralidad en la obra de Teresa Margolles. 2011. Tesis (Maestría) - Universidad Autónoma de Querétaro, Facultad de Bellas Artes. Santiago de Querétaro, ago. 2011. Disponible en: <http://ri.uaq.mx/bitstream/123456789/2330/1/RI001289. PDF $>$. Acceso en: 15 jan. 2016.

MASSOT, Josep. „El arte no paga“, La Vanguardia, 10 dez. 2014.

MATTIO, Javier. „Mudanza perpetua“, La Voz, 24 jan. 2013. Disponible en: < http:// www.lavoz.com.ar/ciudad-equis/mudanza-perpetua>. Acceso en: 15 dez. 2015.

MONETA, Carlos. „España y la industria editorial en Argentina y América Latina en la próxima década: ¡competencia o cooperación?““. Buenos Aires: Universidad Nacional de Tres Febrero, 2009. Disponible en: <http://goo.gl/zU5mpC>. Acceso en: 15 jan. 2016.

MONTFORT, J. S. de. „Levedad fantasmal”. Reseña de Valeria Luiselli, Los ingrávidos. México: HermanoCerdo, 2011. Disponible en: <http://hermanocerdo. com/2011/08/levedad-fantasmal/>. Acceso en: 16 jan. 2016.

MORELLA, José. „La transmigración de los cuerpos, Yuri Herrera“, La tormenta en un vaso, 24 mayo 2013. Disponible en: <http://latormentaenunvaso.blogspot. ch/2013/05/la-transmigracion-de-los-cuerpos-yuri.html>. Acceso en: 17 jan. 2016 . 
MURRENHOFF, Sara. „Die Zeit des magischen Realismus ist vorbei“. Zeit Online, 30 dez. 2014. Disponible en: <http://goo.gl/CP1oNm>. Acceso en: 15 dez. 2015.

OLlero, Carlos. Como pompas de jabón. Madrid: Adeshoras, 2013.

OWEN, Gilberto. „La pompa de jabón“. In: Perseo vencido y otros poemas: antología poética. Ed. Tomás Segovia. Madrid: Huerga \& Fierro Editores, 2006.

RENDÓN ÁNGEL, Juan Edilberto. „Metafórica de las Esferas: aproximación a la trilogía Esferas de Peter Sloterdijk como propuesta redescriptiva y metafórica del espacio“, Revista Observaciones Filosóficas, n. 12, 2011. Disponible en: <http://www.observacionesfilosoficas.net/metaforicadelasesferas.htm>. Acceso en: 16 jan. 2016.

RICHTER, Gerhard. „Mich interessiert der Wahn“, Der Spiegel, n. 33, 15 ago. 2005. Entrevista concedida a Susanne Beyer e Ulrike Knöfel. Disponible en: <http:// www.spiegel.de/spiegel/print/d-41429248.html>. Acceso en: 15 jan. 2016.

RICHTER, Gerhard. „Es geht nur noch um den Preis“. Die Zeit, 22 mar. 2015. Entrevista concedida a Hanno Rauterberg. Disponible en: <http://www.zeit. de/2015/10/gerhard-richter-kunst-preise>. Acceso en: 15 jan. 2016.

SLOTERDIJK, Peter. Esferas: burbujas. Trad. Isidoro Reguera. Madrid: Ediciones Siruela, 2003, v. I. . Esferas: globos. Trad. Isidoro Reguera. Madrid: Ediciones Siruela, 2004, v. II. . Esferas: espumas. Trad. Isidoro Reguera. Madrid: Ediciones Siruela, 2006, v. III.

VOLPI, Jorge. „La literatura latinoamericana ya no existe“, Revista de la Universidad de México, n. 31, 2006: 91.

WIKIPEDIA s.v. Pompa de jabón. <https://es.wikipedia.org/wiki/Pompa_de_ jab\%C3\%B3n>. Acceso en: 18 jan. 2016.

Yvette Sánchez é catedrática de Cultura e Literaturas Hispânicas na Universidade de San Gallen. É Diretora do Centro Latinoamericano-Suizo dessa instituição e coordena o Programa de Doutorado em Estudos Transculturais e Sociais Latinoamericanos. Doutorou-se pela Universidade de Basileia com a tese Coleccionismo y literatura (Madri: Cátedra, 1999). Seus temas de pesquisa são: expressóes culturais dos US Latinos; as poéticas do fracasso; a obra de Enrique Vila-Matas; futebol e literatura; e o microrrelato. E-mail: yvette.sanchez@unisg.ch

Recebido em: 12/01/2016 Aprovado em: 12/02/ 2016 